\title{
Biocomposites Based on Thermoplastic Starch Reinforced with Recycled Paper Cellulose Fibers
}

\section{Amnuay Wattanakornsiri, ${ }^{1, a}$, Sampan Tongnunui ${ }^{2, b}$, Tongsai Jamnongkan ${ }^{3, \mathrm{c}}$ and Claudio Migliaresi ${ }^{4, \mathrm{~d}}$}

${ }^{1}$ Department of Agriculture and Environment, Faculty of Science and Technology, Surindra Rajabhat University, Mueang, Surin, 32000, Thailand

\author{
${ }^{2}$ Division of Biological and Natural Resource Science (Conservation Biology Program), \\ Mahidol University, Kanchanaburi Campus, Sai Yok, Kanchanaburi, 71150, Thailand \\ ${ }^{3}$ Department of Fundamental Science and Physical Education, Faculty of Science at Siracha, \\ Kasetsart University, Siracha, Chonburi, 20230, Thailand \\ ${ }^{4}$ Department of Materials Engineering and Industrial Technologies, University of Trento, \\ Trento, 38050, Italy \\ a*amnuaywattanakornsiri@hotmail.co.th, bsampan_02@hotmail.com, \\ csfscitsj@src.ku.ac.th, ${ }^{\mathrm{d}}$ claudio.migliaresi@ing.unitn.it
}

Keywords: Biocomposites; Thermoplastic starch; Cellulose fibers; Recycled paper; Physical properties

\begin{abstract}
Biocomposites sheets were prepared by compression molding from mixtures of corn starch plasticized by glycerol as matrix and cellulose fibers, extracted from used office paper, as reinforcement filler with contents ranging from 0 to $8 \% \mathrm{wt} / \mathrm{wt}$ of fibers to matrix. Properties of composites were determined by mechanical tensile test, differential scanning calorimetry, thermogravimetric analysis, water absorption measurement, and scanning electron microscopy. The results showed that higher fibers content raised the tensile strength and elastic modulus up to 109\% and $112 \%$, respectively, when compared to the non-reinforced thermoplastic starch (TPS). The addition of the fibers improved the thermal resistance and decreased the water absorption up to $63.6 \%$. Scanning electron microscopy illustrated a good adhesion between matrix and fibers.
\end{abstract}

\section{Introduction}

In recent years, much effort has been made to develop biodegradable materials due to worldwide environment and fossil fuels approaching depletion problems, resulted from petroleum derived plastics [1]. Starch is an important productive polysaccharide in plants and one of the most used materials for producing biodegradable plastics being naturally renewable, cheap and plentiful [2]. It must be converted to TPS for thermal processing ability in the presence of plasticizer and under the action of high temperature and shear force. Only recently has the use of paper pulpfibers, supplied from a company, been applied to reinforce TPS [3]; nonetheless, cellulose fibers extracted from used paper have been never so far employed.

In the present work, we prepared biocomposites based on TPS reinforced by cellulose fibers. TPS was obtained by corn starch using glycerol as plasticizer and cellulose fibers were extracted from used office paper by a deinking-washing process. Properties of TPS/fibers composites were determined by mechanical tensile tests, differential scanning calorimetry (DSC) and thermogravimetric analysis (TGA), water absorption measurements, and morphologies assessment by scanning electron microscopy (SEM).

\section{Methodology}

Cellulose fibers were extracted from used office paper with a deinking washing process. Ordinary corn starch with $27 \%$ amylose content and glycerol with $99.5 \%$ purity were used to prepare TPS as matrix. Starch, dried at $60{ }^{\circ} \mathrm{C}$ for $24 \mathrm{hr}$, and glycerol $(30 \% \mathrm{wt} / \mathrm{wt}$ of glycerol to 
starch) were manually pre-mixed in a polyethylene (PE) bag for 15 min until a powder was obtained.

Biocomposites were prepared from the matrix and varying contents of cellulose fibers $(0,2,4,6$ and $8 \% \mathrm{wt} / \mathrm{wt}$ of fibers to matrix). The matrix and proper amounts of fibers were manually premixed in a PE bag, stored in desiccators for $24 \mathrm{hr}$ for glycerol dispersion, and then mixed using an electric mixer at $160{ }^{\circ} \mathrm{C}$ for $6 \mathrm{~min}$. The resulting mixtures were hot pressed by a compression molding machine at $160{ }^{\circ} \mathrm{C}$ to prepare $1 \mathrm{~mm}$ thick sheets with consecutive times-applied pressures of $10 \mathrm{~min}$-no pressure, $10 \mathrm{~min}-0.74 \mathrm{MPa}$ and $10 \mathrm{~min}-1.48 \mathrm{Mpa}$. After molding, they were cut for the following tests.

Mechanical tensile tests were carried out to measure ultimate tensile strength (UTS) and elastic modulus $(E)$ according to ISO 527 standards.

DSC was carried out to determine thermal transition.

TGA was performed to study thermal degradation.

Water absorption measurements were performed according to ISO 62.

SEM was used to investigate the morphologies of fibers and composites.

\section{Results and Discussion}

The non-reinforced TPS and composites prepared in this work were homogenous, since an agglomeration of cellulose fibers was not visually observed. In this paper, the terms CS-OF0, and CS-OF2, 4, 6 and 8 are used to indicate the non-reinforced TPS, and TPS composites containing 2, 4,6 and $8 \%$ by weight of cellulose fibers, respectively.

The fibers were like ribbons and average fibers length was 1.7 microns and aspect ratio of length/diameter was 92, as evaluated with the aid of ImageJ software on fibers samples SEM micrograph (Fig. 1)

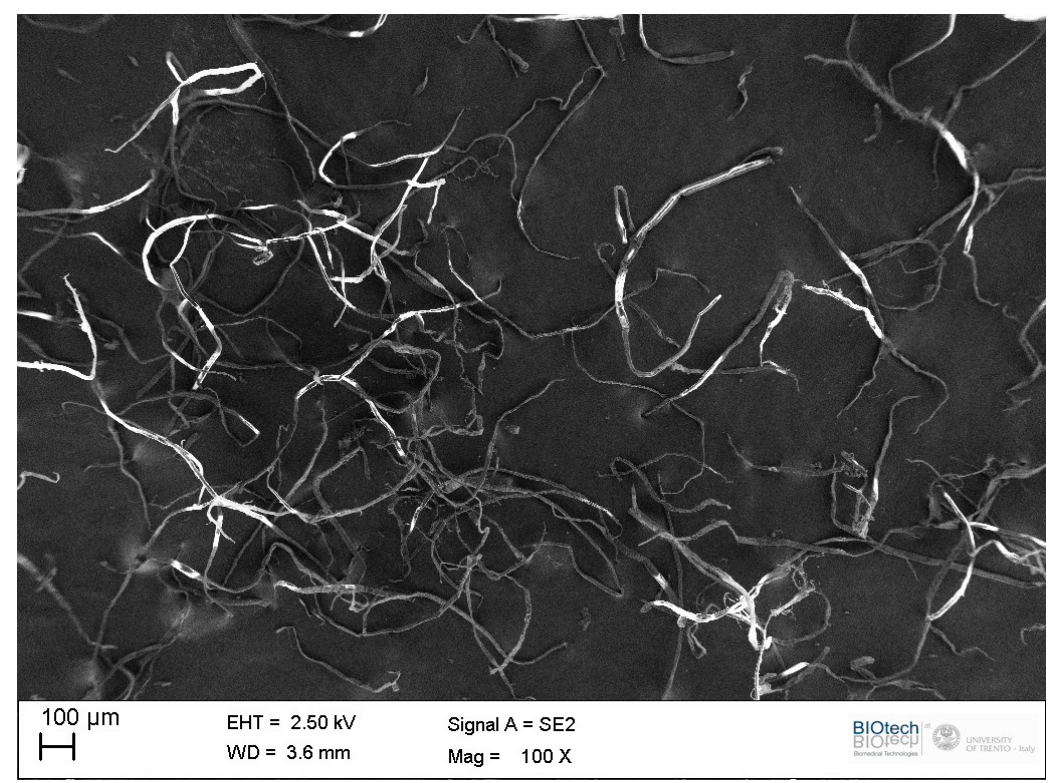

Fig. 1 SEM micrograph of cellulose fibers from used office paper (scale bar: $100 \mu \mathrm{m}$ )

The improvement of the mechanical properties, i.e. UTS and $E$, as a function of cellulose fibers content is presented in Fig. 2. This enhancement confirms the interfacial adhesion and the strong interaction between matrix and cellulose fibers, favored by the chemical similarities between starch and cellulose fibers.

For DSC, two glass transitions were detected in TPS that the lower transition $\left(T_{t 1}\right)$ and the higher transition $\left(\mathrm{T}_{\mathrm{t} 2}\right)$ were clearly attributed to a starch-poor phase and a starch-rich phase, respectively (Table 1). With increasing fibers contents, both transition temperature values shifted to higher temperatures, as a result of interfacial interactions between polar components of fibers and matrix with hydrogen bond [3]. 
With regards to TGA, the degradation temperatures increased with higher fibers content. The results are described by the higher thermal stability of cellulose fibers compared to starch [4]. The weight loss decreased with raising of fibers contents due to the composites had lower water content, when compared to the non-reinforced TPS, at equilibrium [5].
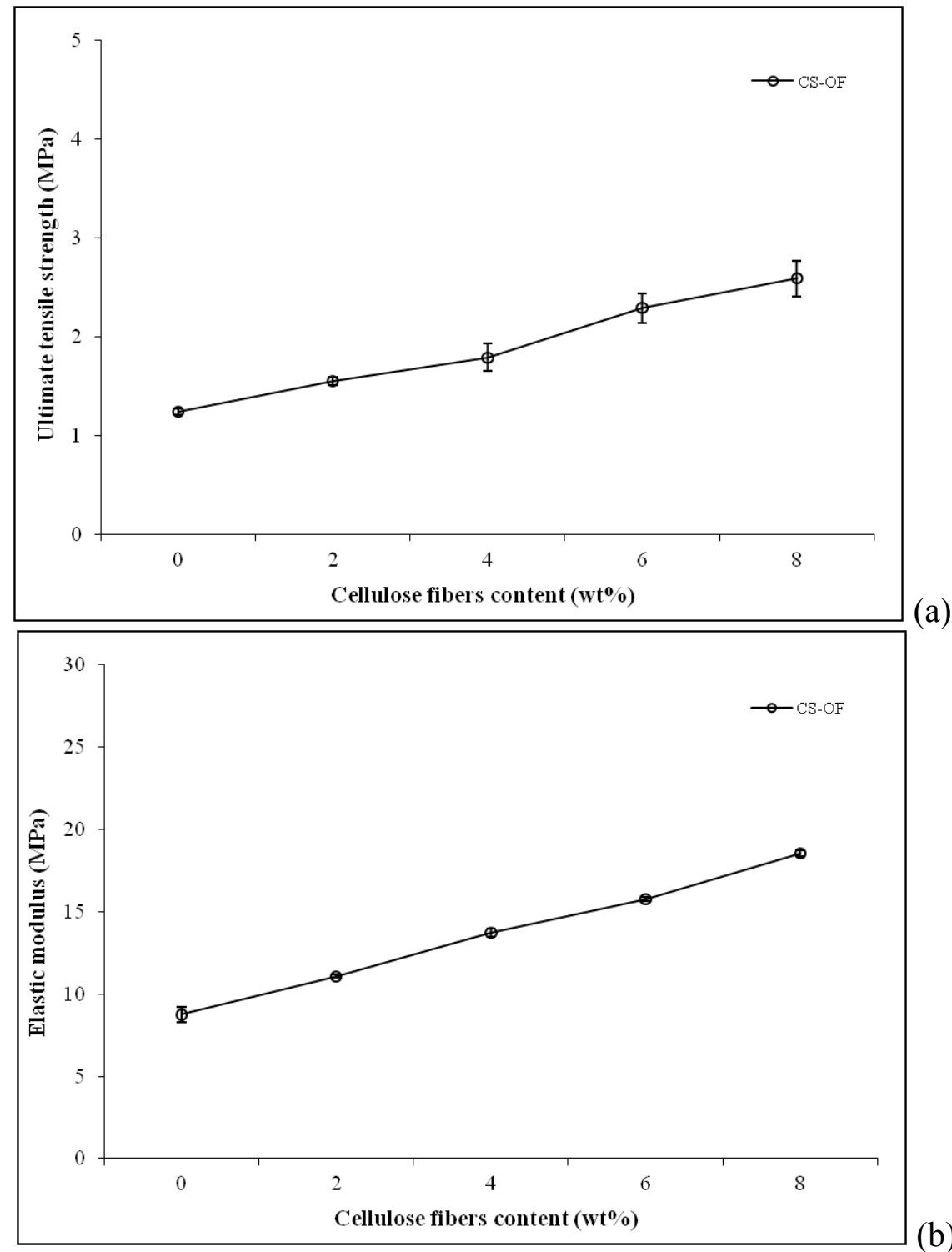

Fig. 2 Effect of cellulose fibers content on the mechanical properties, (a) ultimate tensile strength and (b) elastic modulus, of non-reinforced TPS and composites

Table 1. DSC and TGA results

\begin{tabular}{cccccc}
\hline Composites & \multicolumn{2}{c}{ DSC } & & \multicolumn{2}{c}{ TGA } \\
\cline { 2 - 3 } \cline { 5 - 6 } & $\mathrm{T}_{\mathrm{t} 1}\left({ }^{\circ} \mathrm{C}\right)$ & $\mathrm{T}_{\mathrm{t} 2}\left({ }^{\circ} \mathrm{C}\right)$ & & $\begin{array}{c}\text { Degradation temperature } \\
\left(\text { max DTG peak) }\left({ }^{\circ} \mathrm{C}\right)\right.\end{array}$ & $\begin{array}{c}\text { Weight loss at } 320{ }^{\circ} \mathrm{C} \\
(\%)\end{array}$ \\
\hline CS-OF0 & -69.3 & 62.5 & & 314.7 & 61.4 \\
\hline CS-OF4 & -60.0 & 78.1 & & 318.7 & 56.2 \\
\hline CS-OF8 & -57.5 & 88.3 & & 322.7 & 49.0 \\
\hline
\end{tabular}

The presence of cellulose fibers decreased the amount of absorbed water up to percentage values of minus $63.6 \%$ for CS-OF8 composites when compared to the non-reinforced TPS (Fig. 3). It is described as a direct consequence of the addition of the less hydrophilic cellulose fibers when compared to starch [4]. 


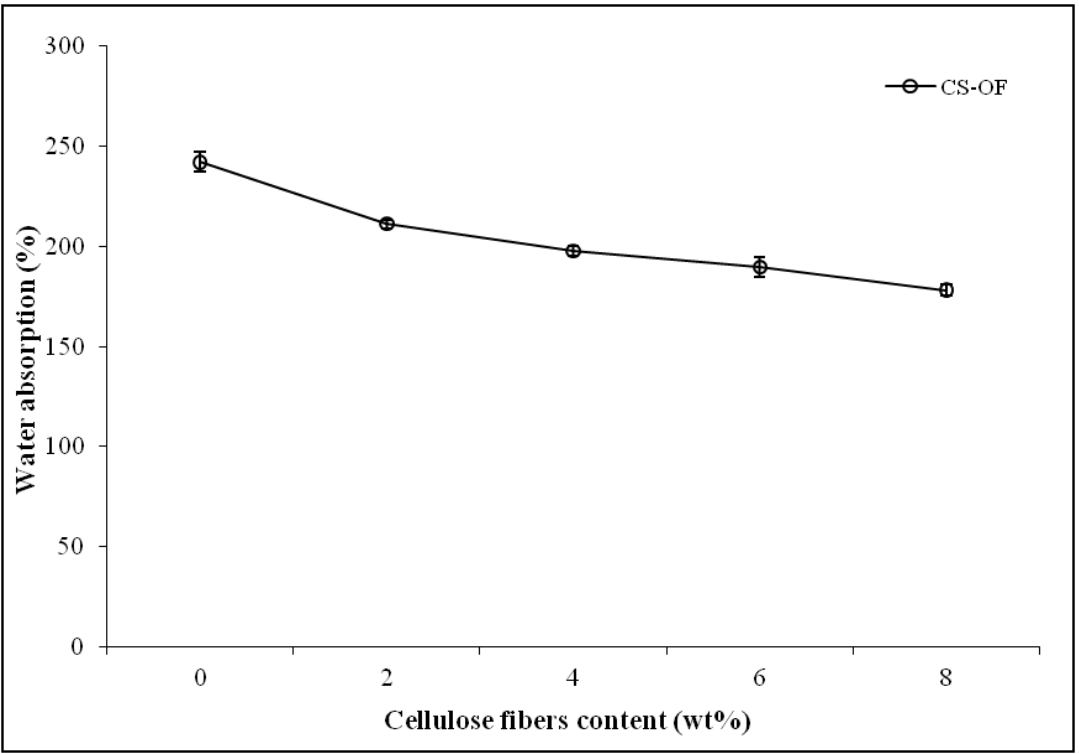

Fig. 3 Water absorption measured according to ISO 62 for non-reinforced TPS and composites

Fig. 4 evidences the good dispersion of fibers in the matrix; projecting broken fibers were detected for all the composites fracture surfaces. Fibers' surfaces expressed to be covered by the matrix and fibers breakage seen was clear in Fig. 5. These clarify to strong interaction between fibers and matrix [6].

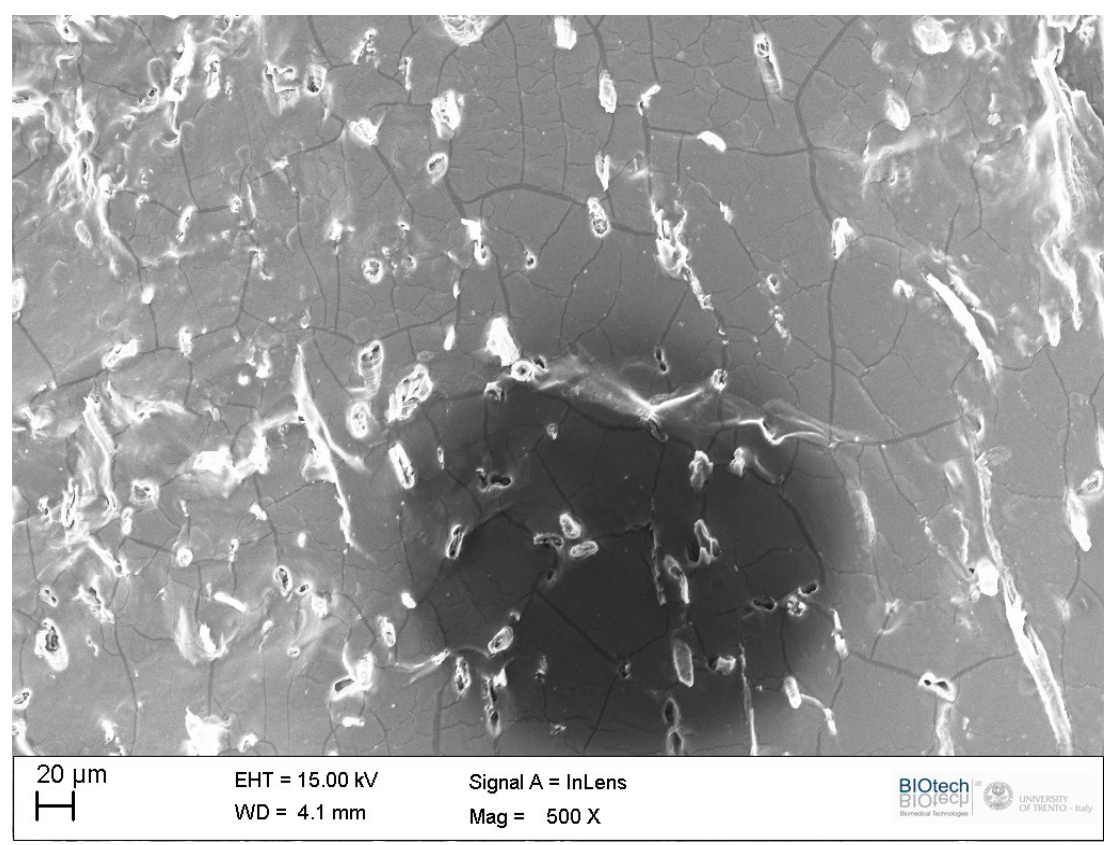

Fig. 4 SEM micrograph of cryo-fractured surface of CS-OF8 composites (scale bar: $20 \mu \mathrm{m}$ ) 


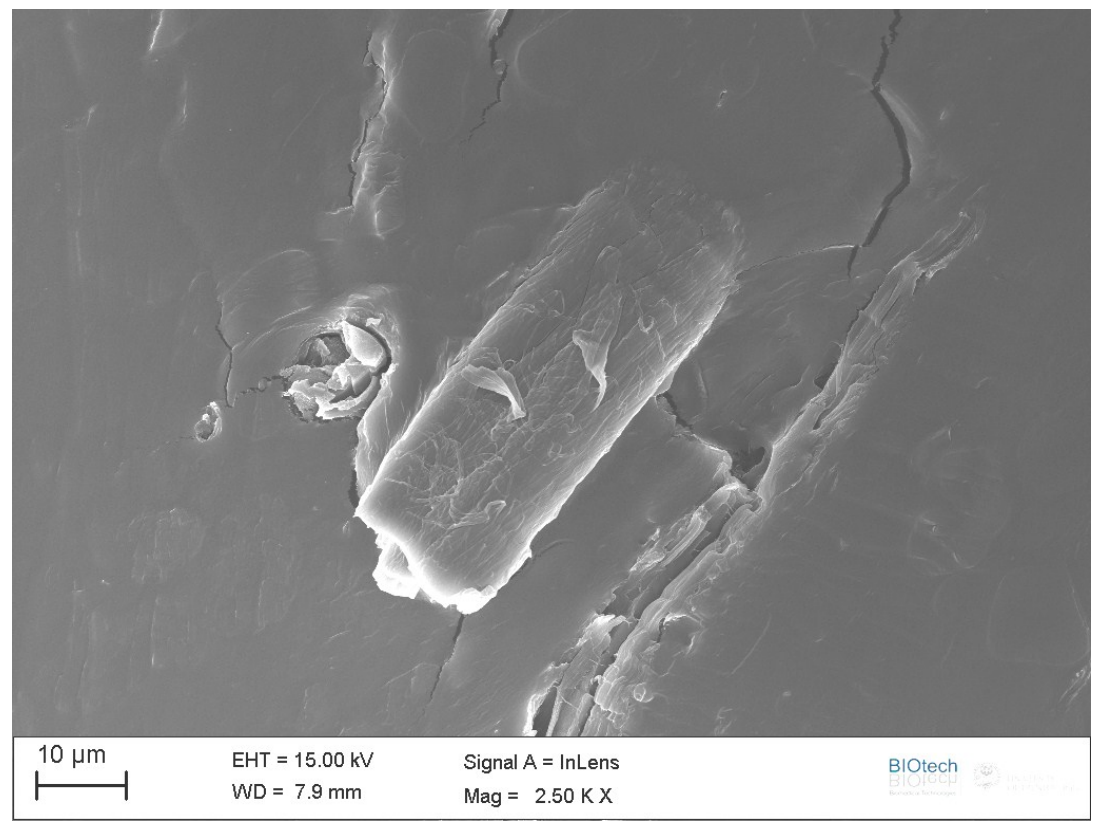

Fig. 5 SEM micrograph of fragile fractured surface of TPS reinforced with $8 \% \mathrm{wt} / \mathrm{wt}$ of fibers to matrix (scale bar: $10 \mu \mathrm{m}$ )

\section{Summary}

This work provided an initial insight to the use and characteristics of recycled paper cellulose fibers as reinforcement in TPS based composites. The presence of the cellulose fibers effectively improved the mechanical properties and thermal resistance, and diminished the water absorption. SEM micrograph showed good adhesion between TPS matrix and cellulose fibers.

\section{References}

[1] A.K. Mohanty, M. Misra, L.T. Drzal, Sustainable bio-composites from renewable resources: opportunities and challenges in the green materials world, J. Polym. Environ. 10 (2002) 19-26.

[2] E.D.M. Teixeira, D. Pasquini, A.A.S. Curvelo, E. Corradini, M.N. Belgacem, A. Dufresne, Cassava bagasse cellulose nanofibrils reinforced thermoplastic cassava starch, Carbohyd. Polym. 78 (2009) 422-431.

[3] L. Averous, N. Boquillon, Biocomposites based on plasticized starch: thermal and mechanical behaviours. Carbohyd. Polym. 56 (2004) 111-122.

[4] I.M.G. Martins, S.P. Magina, L. Oliveira, C.S.R. Freire, A.J.D. Silvestre, C.P. Neto, A. Gandini, New biocomposites based on thermoplastic starch and bacterial cellulose, Compos. Sci. Technol. 69 (2009) 2163-2168.

[5] L. Averous, C. Fringant, L. Moro, Plasticized starch-cellulose interactions in polysaccharide composites. Polymer. 42 (2001) 6571-6578.

[6] A. Wattanakornsiri, S. Tongnunui, Sustainable green composites of thermoplastic starch and cellulose fibers. Songklanakarin J. Sci. Technol. 36 (2014) 149-161. 